\title{
Rapid and Inexpensive Screening of Genomic Copy Number Variations Using a Novel Quantitative Fluorescent PCR Method
}

\author{
Martin Stofanko, ${ }^{1}$ Joan C. Han, ${ }^{2}$ Sarah H. Elsea, ${ }^{3,4}$ Heloísa B. Pena, \\ Higgor Gonçalves-Dornelas, ${ }^{1}$ and Sérgio Danilo Junho Pena ${ }^{1,5}$ \\ ${ }^{1}$ GENE-Núcleo de Genética Médica, Avenida Afonso Pena 3111, 9th Floor, 30130-909 Belo Horizonte, MG, Brazil \\ ${ }^{2}$ Unit on Metabolism and Neuroendocrinology, Eunice Kennedy Shriver National Institute of Child Health and \\ Human Development (NICHD), National Institutes of Health, Bethesda, MD 20892-1103, USA \\ ${ }^{3}$ Departments of Human and Molecular Genetics and Pediatrics, Virginia Commonwealth University School of Medicine, \\ Richmond, VA 23298-0033, USA \\ ${ }^{4}$ Department of Molecular and Human Genetics, Baylor College of Medicine, Houston, TX 77030, USA \\ ${ }^{5}$ Departmento de Bioquímica e Imunologia, Instituto de Ciências Biológicas, Universidade Federal de Minas Gerais, \\ 31270-901 Belo Horizonte, MG, Brazil
}

Correspondence should be addressed to Sérgio Danilo Junho Pena; spena@gene.com.br

Received 26 July 2013; Revised 14 September 2013; Accepted 15 September 2013

Academic Editor: Francisco Blanco-Vaca

Copyright (c) 2013 Martin Stofanko et al. This is an open access article distributed under the Creative Commons Attribution License, which permits unrestricted use, distribution, and reproduction in any medium, provided the original work is properly cited.

\begin{abstract}
Detection of human microdeletion and microduplication syndromes poses significant burden on public healthcare systems in developing countries. With genome-wide diagnostic assays frequently inaccessible, targeted low-cost PCR-based approaches are preferred. However, their reproducibility depends on equally efficient amplification using a number of target and control primers. To address this, the recently described technique called Microdeletion/Microduplication Quantitative Fluorescent PCR (MQF-PCR) was shown to reliably detect four human syndromes by quantifying DNA amplification in an internally controlled PCR reaction. Here, we confirm its utility in the detection of eight human microdeletion syndromes, including the more common WAGR, SmithMagenis, and Potocki-Lupski syndromes with $100 \%$ sensitivity and $100 \%$ specificity. We present selection, design, and performance evaluation of detection primers using variety of approaches. We conclude that MQF-PCR is an easily adaptable method for detection of human pathological chromosomal aberrations.
\end{abstract}

\section{Introduction}

Repetitive DNA accounts for more than 50\% of human genome [1] and is one of the primary driving forces of evolution of all eukaryotes. While mostly harmless, stretches of highly similar sequences flanking genes with essential functions create hotspots prone to undergo unequal recombination during meiosis. The resulting pathological copy number variations (CNVs) [2] include microscopic and submicroscopic deletions and duplications (microdeletions and microduplications) that have been implicated as etiologic factors in many human clinical syndromes. Molecular diagnosis of these aberrations has significantly evolved in resolution from simple metaphase karyotyping to genomewide molecular screens $[3,4]$. However, there are serious limitations to the widespread use of complex diagnostic assays, especially the high cost and rapid obsolescence of the necessary equipment, expensive supplies, and the need for high technical expertise. As a result, pangenomic diagnostic approaches remain scarce in developing countries, where often microdeletion and microduplication syndromes remain undiagnosed. We have described recently the development of a simple, rapid, and inexpensive targeted PCR-based CNV detection method called Microdeletion/Microduplication 


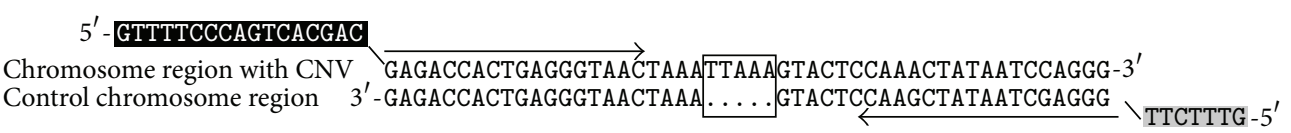

(a)

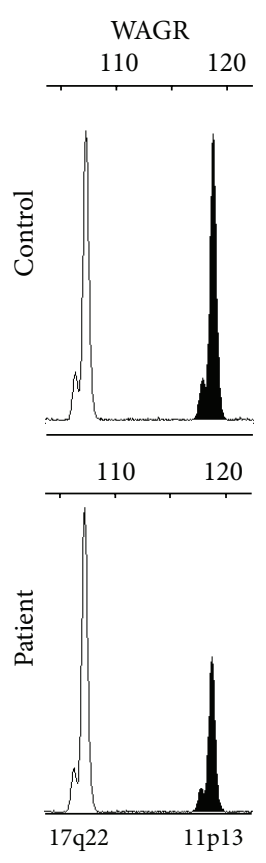

(b)
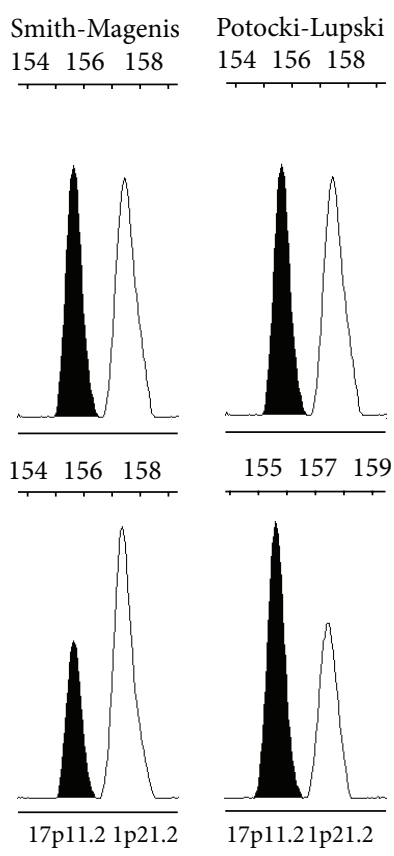

(c)
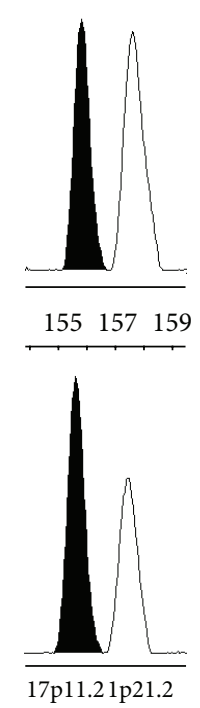

(d)
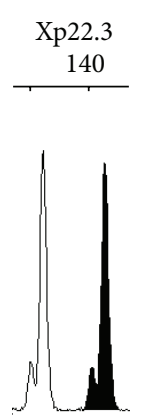

140

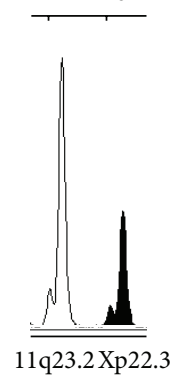

(e)

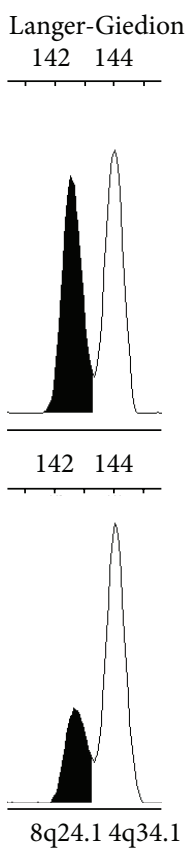

(f)
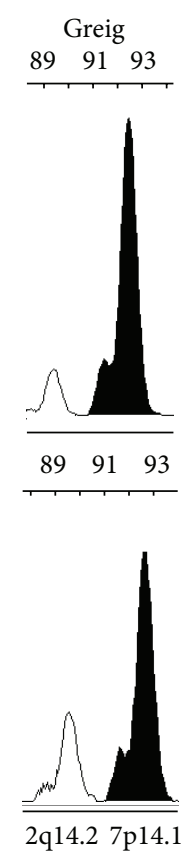

(g)
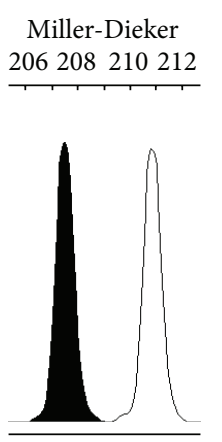

206208210212

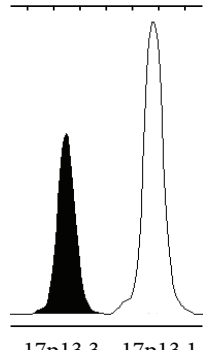

(h) \begin{tabular}{l} 
Saethre-Chotzen \\
122124126128 \\
\hline
\end{tabular}

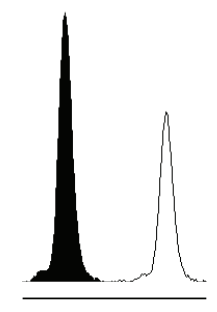

122124126128

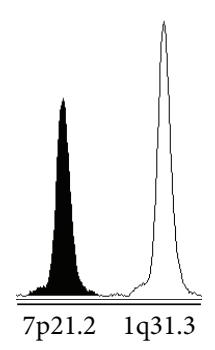

(i)

FIGURE 1: Experimental design and visualization of microdeletion detection using MQF-PCR. (a) Schematic representation of MQF-PCR primer design. Control region with high sequence similarity to the microdeletion critical region and containing 1-10 bp insertion/deletion (empty box) is used to design MQF-PCR primer pair (arrows) that amplifies two fragments of distinct size. The forward primer is extended at $5^{\prime}$ end using M13-40 universal sequence (black box) to allow cost-efficient M13-40-NED fluorescent labeling and reliable quantification of fluorescent signal intensity, while the reverse primer is extended at $5^{\prime}$ end using the PIG-tail (grey box) to improve adenylation of the $3^{\prime}$ end of the forward strand. (b)-(i) Representative electropherograms showing the change in peak areas corresponding to the syndrome-related chromosomes (black) and the peaks representing the control chromosomes (white) between controls and affected individuals. In all panels, approximately $50 \%$ reduction in the peak areas in the affected individuals is observed. Approximate chromosomal locations of the MQF-PCR amplicons are shown.

Quantitative Fluorescent PCR (MQF-PCR) [5]. In our original report, we developed assays for two common microdeletion syndromes, the Williams-Beuren syndrome (7q11.23 microdeletion) and the 22q11.2 microdeletion syndromes and discovered that MQF-PCR could detect both with $100 \%$ sensitivity and 100\% specificity. Additionally, we demonstrated that the same principle could be reliably used for detection of microduplication syndromes, by using samples from patients with the Lubs (MECP2 duplication) syndrome and the 17q11.2 microduplication involving the NF1 gene [5].

Now, we present the development of MQF-PCR primer pairs to detect several other microdeletion syndromes: Wilms tumour, aniridia, genitourinary anomalies, and mental retardation syndrome (WAGR; OMIM: 194072), Smith-Magenis (OMIM: 182290), Potocki-Lupski (OMIM: 610883), microdeletions at Xp22.3 (OMIM: 308100, 308700), Langer-Giedion (OMIM: 150230), Greig cephalopolysyndactyly (OMIM: 175700), Miller-Dieker lissencephaly (OMIM: 247200), and Saethre-Chotzen (OMIM: 101400) syndromes.

\section{Materials and Methods}

2.1. Ethics Statement. DNA samples previously diagnosed with known microdeletion syndromes at GENE-Núcleo de Genética Médica, Belo Horizonte, MG, were anonymized and used in testing the diagnostic procedure. The participants did not provide written or verbal consent and no other formal documented measures were taken. This procedure was approved by the Ethics Committee of Santa Casa de Misericórdia in Belo Horizonte with the registration number CEP 009/2008. WAGR patients were recruited through the International WAGR Syndrome Association. The study was approved by the institutional review board of the National Institute of Child Health and Human Development. Written informed consent was obtained from adults who were competent to provide consent and from the parents or legal guardians of children and adults with cognitive impairment. Assent was obtained from patients who were unable to give consent. Patient samples with Smith-Magenis and PotockiLupski syndromes were collected after informed consent was 
TABLE 1: List of MQF-PCR primers.

\begin{tabular}{|c|c|c|c|}
\hline Syndrome/region & Primer name & $\begin{array}{c}\text { Genomic locations (GRCh37); fragment } \\
\text { size }\end{array}$ & Sequence $\left(5^{\prime} \rightarrow 3^{\prime}\right)$ \\
\hline \multirow{2}{*}{$\begin{array}{l}\text { WAGR [6] } \\
\sim 244 \mathrm{~kb} \text { downstream from } W T 1\end{array}$} & WAGR-MQF-F & chr11:32166342-32166440; 118 bp & AGAATGCAGTGAYACAAAGG $^{\mathrm{a}}$ \\
\hline & WAGR-MQF-R & chr17:53032677-53032764; $107 \mathrm{bp}$ & GGAGGTAGGTAAATCAATCA $^{\mathrm{b}}$ \\
\hline \multirow{2}{*}{$\begin{array}{l}\text { Smith-Magenis/Potocki-Lupski [7] } \\
\sim 9 \mathrm{~kb} \text { upstream from TOM1L2 }\end{array}$} & SMS-MQF-F & chr17:17884450-17884584; 155 bp & TACATTAGAAAAAGAGAGCTGG $^{\mathrm{a}}$ \\
\hline & SMS-MQF-R & chrl:100679142-100679278; 157 bp & CATCATCCTGTTCCССTTTG \\
\hline \multirow{2}{*}{$\begin{array}{l}\mathrm{Xp} 22.3[8] \\
\text { KAL1 }\end{array}$} & Xp22-MQF-F & chrX:8572701-8572822; 136 bp & GAGACCACTGAGGGTAACT $^{\mathrm{a}}$ \\
\hline & $\mathrm{Xp} 22-\mathrm{MQF}-\mathrm{R}$ & chr11:114279747-114279863; 142 bp & AATTTTGAGCATCCTGAAA ${ }^{\mathrm{b}}$ \\
\hline \multirow{2}{*}{$\begin{array}{l}\text { Langer-Giedion [9] } \\
\sim 63 \mathrm{~kb} \text { downstream from UTP23 }\end{array}$} & LGS-MQF-F & chr8:117842056-117842177; 142 bp & AGCAATGGCCATTCCTTAGA $^{\mathrm{a}}$ \\
\hline & LGS-MQF-R & chr4:174188668-174188791; 144 bp & CCATGCAGCACCCYTCAT ${ }^{\mathrm{b}}$ \\
\hline \multirow{2}{*}{$\begin{array}{l}\text { Greig cephalopolysyndactyly [10] } \\
\text { GLI3 }\end{array}$} & GCS-MQF-F & chr7:42088115-42088183; 93 bp & TGCWGAGATCATGGAGAGC $^{\mathrm{a}}$ \\
\hline & GCS-MQF-R & chr2:121708925-121708996; 89 bp & TACRTKAAYCCCYACATGGA ${ }^{\mathrm{b}}$ \\
\hline \multirow{2}{*}{$\begin{array}{l}\text { Miller-Dieker [11] } \\
\text { CRK }\end{array}$} & MDS-MQF-F & chr17:1340129-1340311; 208 bp & TGATTCTCAGGCAGGAGGA $^{\mathrm{a}}$ \\
\hline & MDS-MQF-R & chr17:6962293-6962479; 211 bp & CGACGTAAGGRACTGGAATC $^{\mathrm{b}}$ \\
\hline \multirow{2}{*}{$\begin{array}{l}\text { Saethre-Chotzen [12] } \\
\sim 46 \mathrm{~kb} \text { downstream from TWIST1 }\end{array}$} & SCS-MQF-F & chr7:19108525-19108628; 124 bp & TGGATATTTGTGYTAYTTCCTT ${ }^{\mathrm{a}}$ \\
\hline & SCS-MQF-R & chrl:195731420-195731527; 128 bp & TGCATACTMCACAATTAATTRTGTG \\
\hline
\end{tabular}

TABLE 2: MQF-PCR detection of eight human microdeletion syndromes.

\begin{tabular}{|c|c|c|}
\hline Syndrome & Patient & Z-statistics score \\
\hline \multirow{9}{*}{ WAGR } & 3.3 & -5.14 \\
\hline & $6.3 \mathrm{~A}$ & -5.23 \\
\hline & 8.3 & -5.72 \\
\hline & $17.3 \mathrm{~A}$ & -5.47 \\
\hline & $18.3 \mathrm{~A}$ & -5.41 \\
\hline & 21.3 & -5.55 \\
\hline & $24.3 \mathrm{~A}$ & -5.55 \\
\hline & $29.3 \mathrm{C}$ & -5.44 \\
\hline & GM06803 & -6.97 \\
\hline \multirow{11}{*}{ Smith-Magenis } & SMS105 & -4.42 \\
\hline & SMS123 & -5.19 \\
\hline & SMS135 & -4.18 \\
\hline & SMS162 & -4.27 \\
\hline & SMS167 & -3.69 \\
\hline & SMS170 & -4.38 \\
\hline & SMS179 & -2.93 \\
\hline & SMS182 & -4.87 \\
\hline & SMS217 & -4.26 \\
\hline & SMS293 & -4.18 \\
\hline & SMS336 & -5.48 \\
\hline \multirow{3}{*}{ Potocki-Lupski } & SMS224 & 2.81 \\
\hline & SMS338 & 5.64 \\
\hline & 11166 & 8.72 \\
\hline Xp22.3 & Simulated patient & $0.01 \pm 0.14^{\mathrm{a}}$ \\
\hline \multirow{2}{*}{ Langer-Giedion } & GM09888 & -7.40 \\
\hline & 12550 & -7.12 \\
\hline Greig cephalopolysyndactyly & GM10925 & -3.12 \\
\hline Miller-Dieker lissencephaly & GM09208 & -6.36 \\
\hline Saethre-Chotzen & 10051 & -6.43 \\
\hline
\end{tabular}

\footnotetext{
${ }^{a}$ Arithmetic mean of Z-scores, standard deviation of mean.
} 


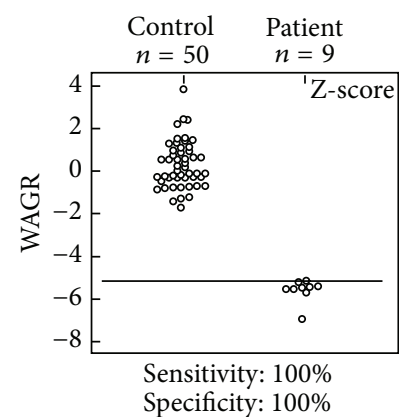

(a)

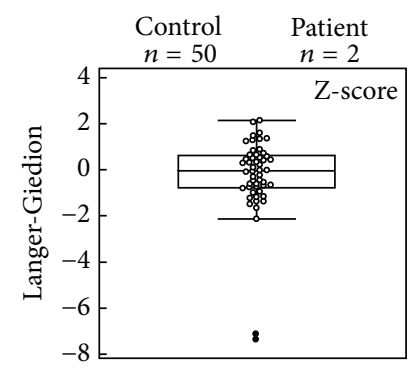

(e)

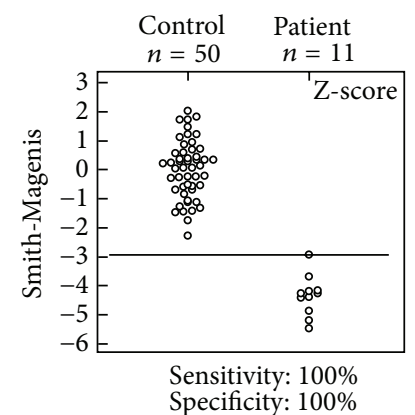

(b)

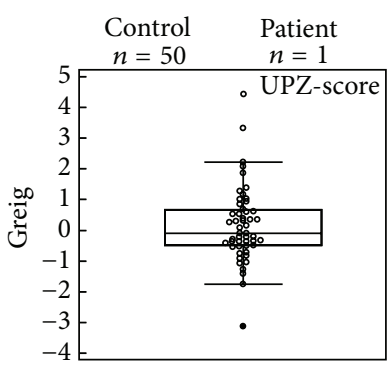

(f)

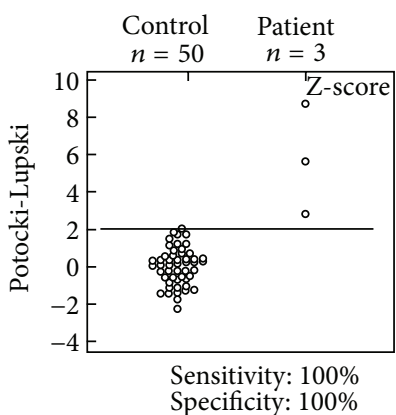

(c)

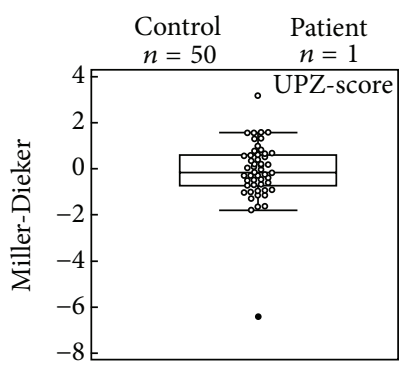

(g)

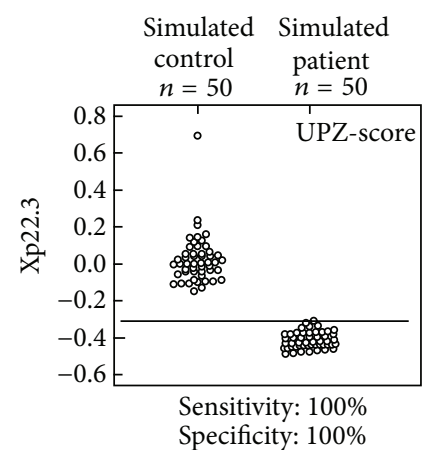

(d)

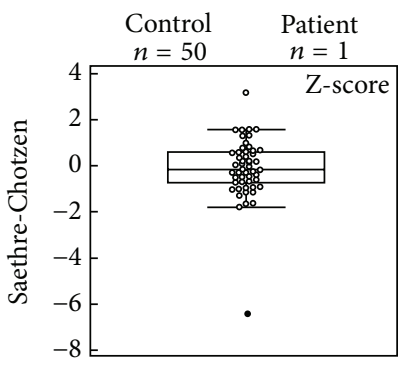

(h)

FIgure 2: Performance of MQF-PCR in detection of various CNVs. Interactive dot diagrams of ROC curve analysis of Z-score statistics in WAGR (a), Smith-Magenis (b), Potocki-Lupski (c), and Xp22.3 deletion detection (d). The MQF-PCR primers achieved 100\% detection sensitivity and 100\% detection specificity. Box-and-Whisker plot of Z-score statistics obtained for Langer-Giedion (e), Greig cephalolysyndactyly (f), Miller-Dieker lissencephaly (g), and Saethre-Chotzen (h) microdeletion syndromes. Positive samples (full circle) are shown as outliers. In all panels, the number of controls and patients analyzed is given.

obtained and in accordance with local institutional review board approved protocols from Virginia Commonwealth University and/or Michigan State University.

2.2. Patients. Genomic DNA from normal male and female individuals and from individuals previously diagnosed with microdeletion syndromes diagnosed at GENE Núcleo de Genética Médica, Belo Horizonte, MG, Brazil, was isolated as described [5]. WAGR sample GM06803 was obtained from Coriell Cell Repositories (Camden, New Jersey, USA). The remaining WAGR samples diagnosed by genome-wide aCGH were described previously [6]. DNA samples of SmithMagenis and Potocki-Lupski patients diagnosed by FISH or metaphase karyotyping were published previously [7]. In order to simulate Xp22.3 microdeletions, we used normal female and male samples as control individuals and affected samples, respectively. The Saethre-Chotzen syndrome patient 10051 had microdeletion at 7p21.1 diagnosed by aCGH. The Langer-Giedion syndrome patient 12550 showed cytogenetically visible partial deletion of the long arm of chromosome 8 and was diagnosed at our clinic. The remaining samples were obtained from Coriell Cell Repositories: GM09888 (Langer-Giedion), GM10925 (Greig cephalopolysyndactyly), and GM09208 (Miller-Dieker lissencephaly).
2.3. MQF-PCR Primer Selection, Assay Design, and Analysis. MQF-PCR takes advantage of the presence of highly similar sequences in distinct parts of human genome, which differ in length by a few base pairs (Figure 1(a)). A detailed literature search of previously published molecular genetic analyses was performed for each of the syndromes in order to determine minimal critical regions suitable for MQF-PCR primer design (Table 1, GRCh37 human genome assembly) $[6-12,14]$. These regions were used as queries in Basic Local Alignment Search Tool (http://blast.ncbi.nlm.nih.gov/). A single PCR primer pair (arrows in Figure 1(a)) was then designed, capable of amplification of two fragments, one that locates to the critical genomic region of disease and another, shorter or longer, that serves as CNV-free control fragment (Figure 1(a); Table 1). In order to reliably quantify the differently sized amplicons, we employed a cost-efficient method of fluorescent labeling of PCR products with the common M13-40-NED primer (Figure 1(a)) [13]. PCR amplification, amplicon separation, and data collection and analysis were performed as described in Stofanko et al. [5]. We used Receiver Operating Characteristic (ROC) analysis of the Z or UPZ score statistics [15, 16] using MedCalc v12 (MedCalc Software, Mariakerke, Belgium). Box-and-Whisker plots were also constructed using MedCalc [17]. 95\% confidence intervals of true positives, false positives, true negatives and false negatives were calculated 
TABLE 3: Sensitivity and specificity of MQF-PCR tests in detection of WAGR, Smith-Magenis, Potocki-Lupski and simulated Xp22.3 microdeletion syndromes.

\begin{tabular}{|c|c|c|c|c|}
\hline \multirow{2}{*}{ Syndrome } & \multicolumn{4}{|c|}{ Probability estimate ( $95 \%$ confidence interval) } \\
\hline & True positive & False positive & True negative & False negative \\
\hline WAGR & $100 \%(66-100 \%)$ & $0 \%(0-7 \%)$ & $100 \%(93-100 \%)$ & $0 \%(0-34 \%)$ \\
\hline Smith-Magenis & $100 \%(72-100 \%)$ & $0 \%(0-7 \%)$ & $100 \%(93-100 \%)$ & $0 \%(0-28 \%)$ \\
\hline Potocki-Lupski & $100 \%(29-100 \%)$ & $0 \%(0-7 \%)$ & $100 \%(93-100 \%)$ & $0 \%(0-71 \%)$ \\
\hline Xp22.3 & $100 \%(93-100 \%)$ & $0 \%(0-7 \%)$ & $100 \%(93-100 \%)$ & $0 \%(0-7 \%)$ \\
\hline
\end{tabular}

using the Fisher's exact test [18] in GraphPad Prism 6 (GraphPad software, CA, USA).

\section{Results and Discussion}

In affected individuals, because of the deletions or duplications, the amount of template DNA corresponding to the syndrome's critical region is inherently halved or doubled, respectively, in comparison with the control region when equal amounts of DNA from the affected and control individuals are dispensed in the assay system. Following PCR, this translates into an approximately $50 \%$ reduction or increase in the area under the electrophoretic peak of the amplicon from the critical microdeletion region (Figures 1(b)-1(i)). For example, in the detection of the WAGR syndrome (Figure 1(b)), we observed in normal controls a ratio close to $1: 1$ of the peak that corresponds to the WAGR critical region at 11p13 (black) and the control peak at 17q22 (white). In a hemizygous patient, the peak area ratio changed to approximately $1: 2$ (black/white), which reflects the template DNA dosage change. Similar reduction in peak area ratios was noted for Smith-Magenis, Langer-Giedion, Greig cephalopolysyndactyly, Miller-Dieker lissencephaly, and Saethre-Chotzen syndromes even if the peak area ratio in controls was not exactly the expected 1:1 ratio, presumably because amplicon-specific factors influence the efficiency of PCR (Figures 1(c) and 1(e)-1(i)). Figure 1(d) shows detection of autosomal duplication of $17 \mathrm{p} 11.2$ that causes PotockiLupski syndrome. In this patient, the peak area ratio changed from about $1: 1$ to about $3: 2$ (black/white), which reflects the template DNA dosage change. Since the number of patients available for testing is limited in rare syndromes, in the case of the Xp22.3 deletions (Figure 1(e)) we used female samples (XX) as controls and male DNA (XY) as a simulated model for affected patients. This way we could obtain a better picture of the performance of our method on a larger scale and extend its use to include diagnosis of deletions in the Xp22.3 region in male patients for whom only the control fragment would be detected. Finally, in order to correct for the observed uneven amplification efficiency, we normalized our data to a reference sample of mixed DNA from 100 individuals that was processed at the same time [5]. Standard deviation $Z$-scores or pseudo-Z scores [15] were then calculated for each sample (Table 2), and the performance of each assay was evaluated by ROC analysis [16] (Figures 2(a)-2(d)). Instances with fewer than five positive patients were assessed using Box-and-Whisker plot [17] (Figures 2(e)-2(h)). We achieved unbiased and reproducible PCR amplification in
WAGR and Smith-Magenis syndromes and the simulated Xp22.3 deletions with 100\% detection sensitivity and 100\% exclusion specificity. Similarly, the results for patients with rarer syndromes appeared as outliers in corresponding Boxand-Whisker plots. The $95 \%$ confidence intervals for the sensitivity and specificity of MQF-PCR tests for WAGR, Smith-Magenis, Potocki-Lupski, and the simulated Xp22.3 syndromes are shown in Table 3.

It should be noted that a limitation of this protocol for diagnosing patients with 11 p13 region deletions is that it is $100 \%$ sensitive only in patients with aniridia because the targeted critical region lies between PAX6 (the gene responsible for aniridia) and $W T 1$ (the gene responsible for Wilms tumor and genitourinary anomalies); this protocol would fail to detect 11 p13 deletions that involve WT1, but spare PAX6. Such patients would not be considered to have classic WAGR syndrome however, and this MQF-PCR could be easily modified to target other critical regions to diagnose proximal 11p deletion and/or Potocki-Shaffer syndromes.

\section{Conclusion}

Here we report development of detection primers for 8 human microdeletion syndromes using the recently described MQF-PCR. We showed that the method is easily adaptable to detect any pathological CNV with high accuracy. With the expansion of the capability to diagnose even more disease-related CNVs, MQF-PCR appears to be a reliable, low cost, and rapid detection method, especially for use in developing countries.

\section{Disclosure}

The Microdeletion/Microduplication Quantitative Fluorescent PCR (MQF-PCR) test, being described herein, is the subject of a patent application (No. BR102012021281-1) by GENE-Nucleo de Genetica Médica in the Instituto Nacional de Propriedade Intelectual (INPI) of Brazil, entitled "Método e kit para identificação de microdeleções cromossômicas humanas pela quantificação fluorescente de PCR (MQFPCR)".

\section{Conflict of Interests}

Joan C. Han, Sarah H. Elsea, Heloísa B. Pena and Higgor Gonçalves-Dornelas declare that they have no conflict of interests. 


\section{Acknowledgments}

The authors thank Conselho Nacional de Desenvolvimento Científico e Tecnológico Grant no. 401983/2010-2 for providing financial funding for this work. The research was also supported in part by the Intramural Research Program of the Eunice Kennedy Shriver National Institute of Child Health and Human Development (ZIAHD008898). We thank PRISMS (SMS support group) and the patients and their families for their participation and support of research.

\section{References}

[1] E. S. Lander, L. M. Linton, B. Birren et al., "Initial sequencing and analysis of the human genome," Nature, vol. 409, pp. 860921, 2001.

[2] Y. C. Tang and A. Amon, "Gene copy-number alterations: a cost-benefit analysis," Cell, vol. 152, pp. 394-405, 2013.

[3] A. C. J. Gijsbers and C. A. L. Ruivenkamp, "Molecular karyotyping: from microscope to SNP arrays," Hormone Research in Paediatrics, vol. 76, no. 3, pp. 208-213, 2011.

[4] P. L. Crotwell and H. E. Hoyme, "Advances in whole-genome genetic testing: from chromosomes to microarrays," Current Problems in Pediatric and Adolescent Health Care, vol. 42, no. 3, pp. 47-73, 2012.

[5] M. Stofanko, H. Goncalves-Dornelas, P. S. Cunha, H. B. Pena, A. M. Vianna-Morgante, and S. D. Pena, "Simple, rapid and inexpensive quantitative fluorescent PCR method for detection of microdeletion and microduplication syndromes," PloS ONE, vol. 8, Article ID e61328, 2013.

[6] J. C. Han, Q.-R. Liu, M. Jones et al., "Brain-derived neurotrophic factor and obesity in the WAGR syndrome," The New England Journal of Medicine, vol. 359, no. 9, pp. 918-927, 2008.

[7] C. N. Vlangos, D. K. C. Yim, and S. H. Elsea, "Refinement of the Smith-Magenis syndrome critical region to $\sim 950 \mathrm{~kb}$ and assessment of 17p11.2 deletions. Are all deletions created equally?" Molecular Genetics and Metabolism, vol. 79, no. 2, pp. 134-141, 2003.

[8] L. M. B. Oliveira, S. B. Seminara, M. Beranova et al., "The importance of autosomal genes in Kallmann syndrome: genotypephenotype correlations and neuroendocrine characteristics," The Journal of Clinical Endocrinology and Metabolism, vol. 86, no. 4, pp. 1532-1538, 2001.

[9] J. Hou, J. Parrish, H.-J. Ludecke et al., "A 4-megabase YAC contig that spans the Langer-Giedion syndrome region on human chromosome 8q24.1: use in refining the location of the trichorhinophalangeal syndrome and multiple exostoses genes (TRPS1 and EXT1)," Genomics, vol. 29, no. 1, pp. 87-97, 1995.

[10] J. J. Johnston, I. Olivos-Glander, J. Turner et al., "Clinical and molecular delineation of the greig cephalopolysyndactyly contiguous gene deletion syndrome and its distinction from acrocallosal syndrome," The American Journal of Medical Genetics A, vol. 123, no. 3, pp. 236-242, 2003.

[11] J. R. Østergaard, J. Graakjær, C. Brandt, and N. H. Birkebæk, "Further delineation of 17p13.3 microdeletion involving CRK. The effect of growth hormone treatment," European Journal of Medical Genetics, vol. 55, no. 1, pp. 22-26, 2012.

[12] D. Johnson, S. W. Horsley, D. M. Moloney et al., "A comprehensive screen for TWIST mutations in patients with craniosynostosis identifies a new microdeletion syndrome of chromosome band 7p21.1," The American Journal of Human Genetics, vol. 63, no. 5, pp. 1282-1293, 1998.
[13] M. Schuelke, "An economic method for the fluorescent labeling of PCR fragments," Nature Biotechnology, vol. 18, no. 2, pp. 233234, 2000.

[14] B. M. Kamath, B. D. Thiel, X. Gai et al., "SNP array mapping of chromosome 20p deletions: genotypes, phenotypes, and copy number variation," Human Mutation, vol. 30, no. 3, pp. 371-378, 2009.

[15] J. R. Lanzante, "Resistant, robust and non-parametric techniques for the analysis of climate data: theory and examples, including applications to historical radiosonde station data," International Journal of Climatology, vol. 16, no. 11, pp. 11971226, 1996.

[16] M. H. Zweig and G. Campbell, "Receiver-operating characteristic (ROC) plots: a fundamental evaluation tool in clinical medicine," Clinical Chemistry, vol. 39, no. 4, pp. 561-577, 1993.

[17] J. V. Tukey, Exploratory Data Analysis, Addison-Wesley, Reading, Mass, USA, 1977.

[18] R. A. Fisher, Statistical Methods for Research Workers, Oliver and Boyd, Edinburgh, UK, 1925. 


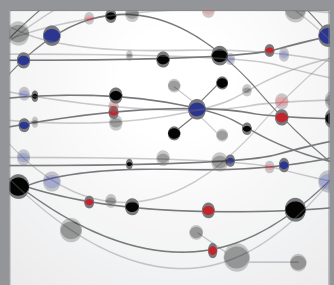

The Scientific World Journal
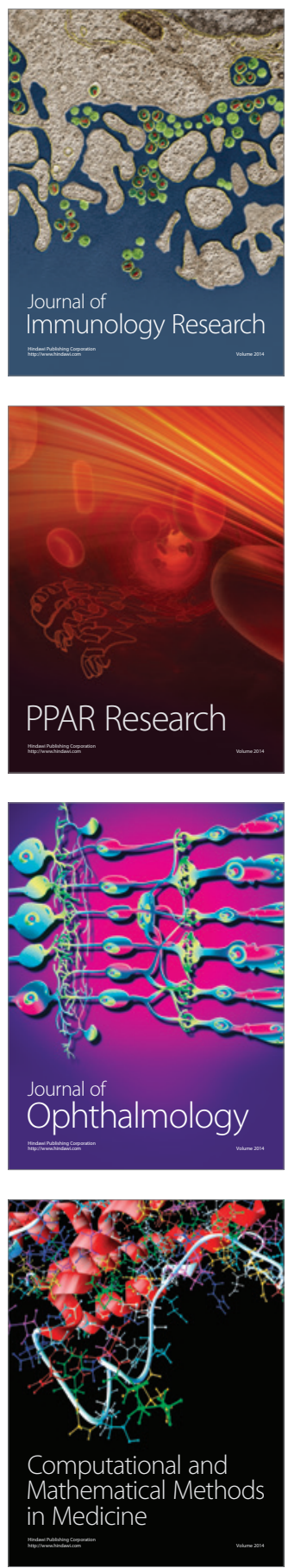

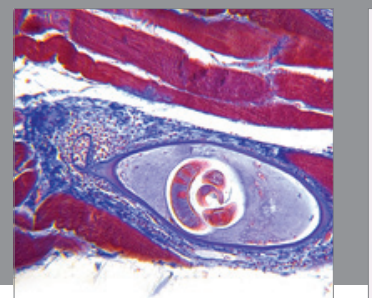

Gastroenterology

Research and Practice
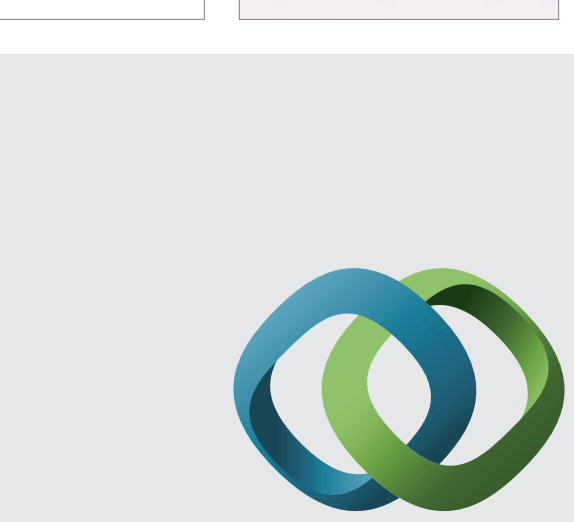

\section{Hindawi}

Submit your manuscripts at

http://www.hindawi.com
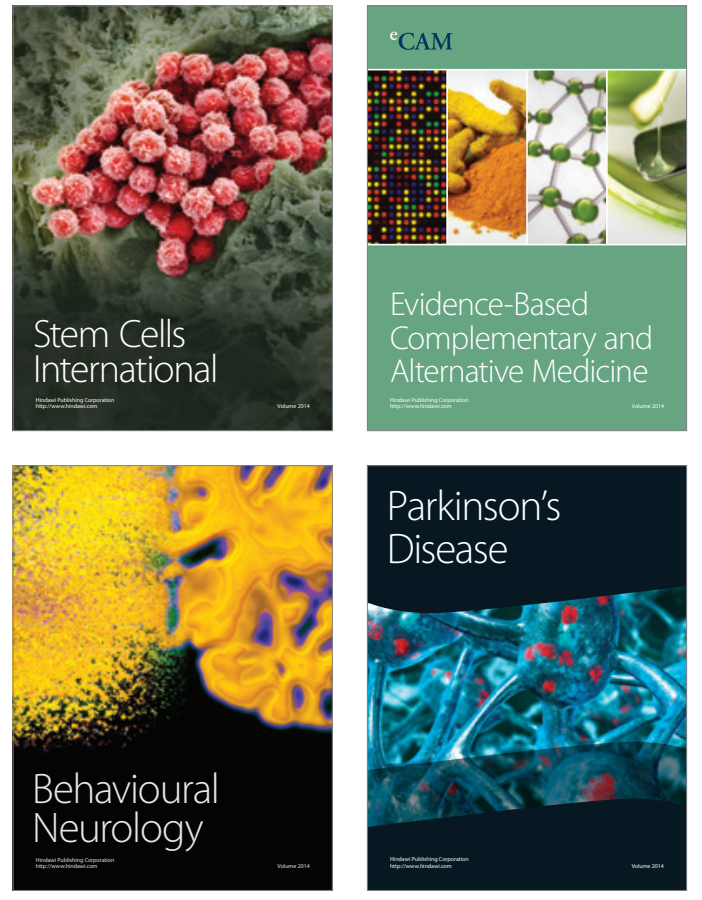
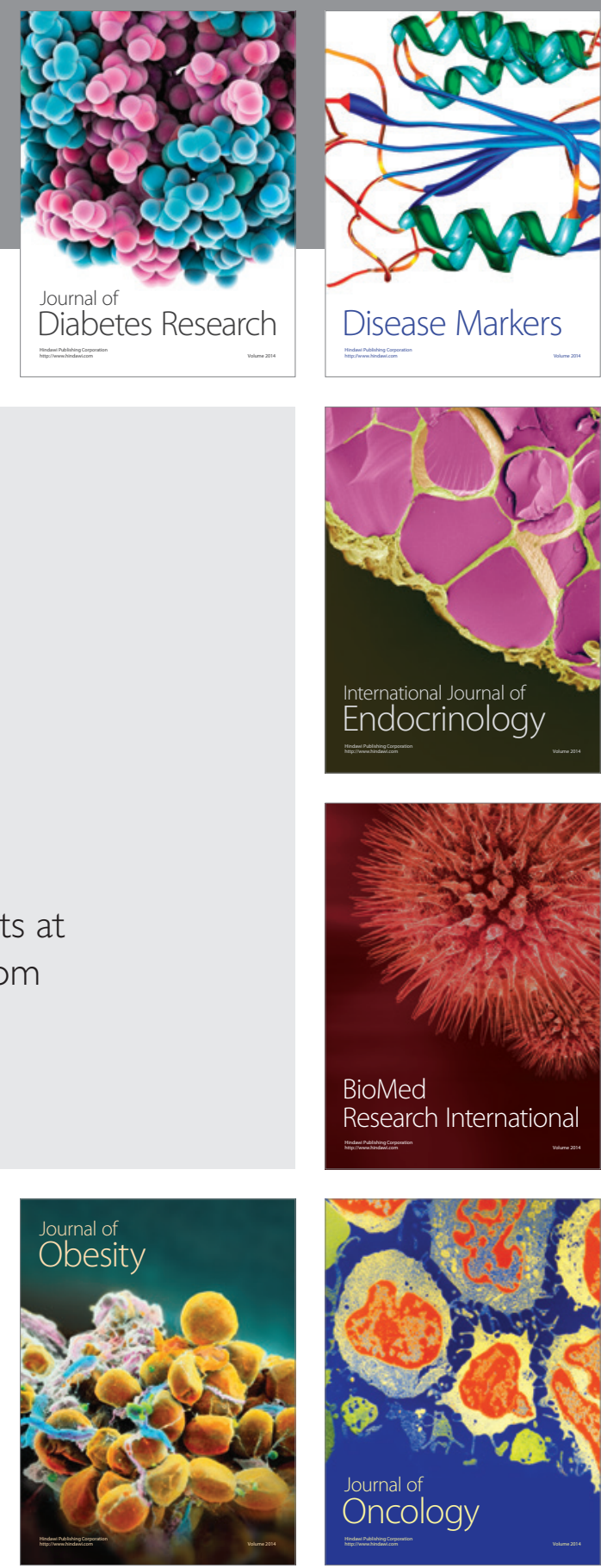

Disease Markers
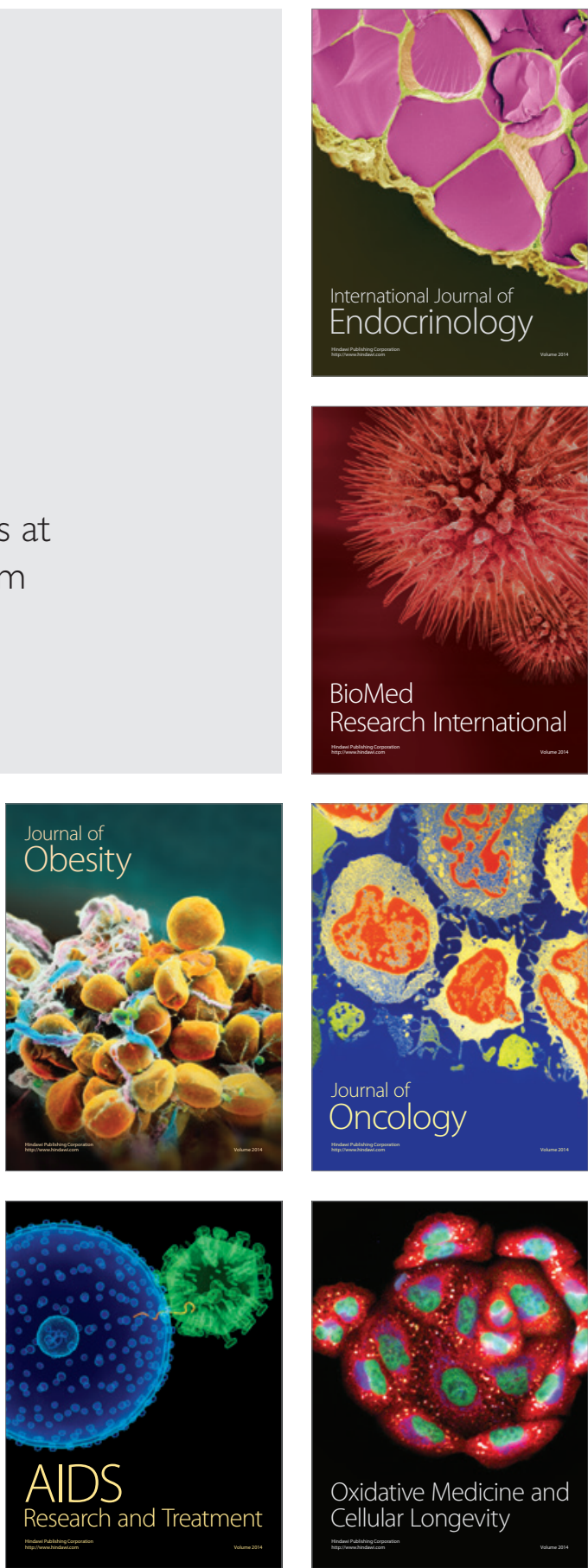